\title{
Para aprender e ensinar antropologias
}

\author{
AMANDA HORTA \\ UNIVERSIDADE FEDERAL DE CIÊNCIAS DA SAÚDE DE PORTO ALEGRE (UFCSPA) \\ PORTO ALEGRE/RS, BRASIL \\ HTTPS://ORCID.ORG/0000-0002-0602-5669 \\ CLAUDIA BONGLANINO \\ FUNDAÇÃO RENOVA, BELO HORIZONTE/MG, BRASIL \\ LABORATÓRIO DE ANTROPOLOGIA E HISTÓRIA DO MUSEU NACIONAL, UNIVERSIDADE FEDERAL DO RIO DE JANEIRO \\ (LAH/MN/UFRJ), RIO DE JANEIRO/RJ, BRASIL \\ HTTPS://ORCID.ORG/OOOO-0003-IS3I-2093
}

\begin{abstract}
Abertura
Instituída como ciência autônoma na segunda metade do século XIX, a antropologia se definiu como disciplina voltada, inicialmente, para o estudo dos Outros. Neste artigo, nós - e dizemos nós porque somos duas as autoras deste texto, Amanda Horta e Claudia Fioretti Bongianino - iremos refletir sobre a urgência de instituir e disseminar formas de aprender e ensinar antropologias capazes de incorporar seu potencial reflexivo e de subverter, assim, seu mito de origem. Através de duas experiências situadas ao longo de nossas trajetórias de formação e atuação enquanto antropólogas, colocaremos em operação um conjunto de problemáticas vinculadas ao método de ensino ancorado na dualidade Nós versus Outros, argumentando que ele tende a produzir antropólogos e antropólogas identificadas com o Nós nessa dualidade - e que isso é politicamente perigoso.
\end{abstract}

\section{Uma anedota: "nós e a seita da antropologia"}

A forma como a antropologia tende a ser ensinada em cursos introdutórios parece ancorada na ideia de que ela é um tipo de sociedade secreta. O modo como isso se dá carrega certo ar de magia: a 
oposição entre o intelectual ${ }^{1}$ europeu, que pensa e compartilha o conhecimento que produz com sua alta sociedade, e os povos distantes, que são por ele pensados, são a pedra de toque da narrativa didática. Mas aquilo que a princípio parecia um pequeno e distante séquito de homens brancos europeus familiarizados com o universo acadêmico, aos poucos, passa a incluir também o professor ou a professora.

De fato, são muitos os livros de introdução à antropologia que começam narrando a história do intelectual - homem branco europeu - numa sala repleta de livros, escrevendo sobre a vida de povos distantes, descritos como Outros em relação a ele. Talvez a universidade não seja europeia, mas a professora ou o professor é um intelectual, provavelmente versado em francês e inglês, e isso parece autorizar sua entrada no time dos brancos europeus. A(o) docente, então, convida gentilmente as(os) estudantes a pensarem como se fossem, eles mesmos, antropólogos também. Afinal, são seus pupilos sua "sociedade", em sentido restrito. Se a sociedade dos primeiros antropólogos no século XIX estava incluída, os alunos e as alunas em cada sala de aula estavam incluídos também, por extensão. Assim, na primeira década dos anos 2000, quando nós, Amanda e Claudia, éramos alunas de graduação em um curso de antropologia de uma grande universidade brasileira, parecíamos ser todas(os) - alunas(os) e professoras(os) - uma extensão daquele séquito de homens brancos e europeus, produtores e consumidores dos conhecimentos científicos. Uma sociedade secreta, produzida como que em um passe de mágica: a antropologia é uma ciência que, supostamente, só se aprende de dentro.

Os Outros sobre quem se conversava naquelas aulas eram o obscuro resto do mundo ${ }^{2}$, habitado por uma gente absorta em um verdadeiro mar de crenças ${ }^{3}$, populações chamadas, no Brasil, de povos tradicionais, mas que são descritas com mais precisão como "povos historicamente marginalizados" (Collins et al., 2020). A marca desses grupos era apresentada como sendo a diferença que os separava do intelectual branco e sua sociedade e, por extensão, da(o) professora(o), bem como de seus pupilos e pupilas. Partindo do princípio de que a natureza humana é, em toda parte, a mesma, caberia à antropologia explicar a grande diversidade cultural da espécie (cf. Geertz, 1978). Os evolucionistas o teriam feito afirmando que o desenvolvimento da humanidade passa pelos mesmos estágios em todos os povos. Os supostos selvagens não eram maus, nem incapazes inveterados, eram apenas atrasados, diziam, complacentes, autores como Edward Burnett Tylor e John Ferguson McLennan. No alto do pódio estariam eles próprios, os pais fundadores da antropologia. Junto a eles estariam as professoras(es) (que pode não ser europeu ou estadunidense, mas é anglófono ou francófono) e as alunas(os) em iniciação.

Como sabemos, a crítica veio já nas primeiras décadas do século XX. A antropologia estaria roubando no jogo: postulou uma superioridade europeia e descreveu o mundo todo a partir deste critério. "Mas podemos começar a nos atentar para isso, como fizeram os evolucionistas. Aprendamos com o

1 Neste texto, utilizamos o masculino (como em "o intelectual") para explicitar aspectos machistas e patriarcais da cultura hegemônica de "matriz europeia" (expressão que usamos no sentido de Harari, 2014). Apesar de estarmos cientes desses aspectos e de que eles se expressam também na linguagem, neste texto optamos por apenas explicitá-los, permanecendo à margem da discussão. Adiante, no texto, daremos preferência a formulações como "as(os) professoras(es)" (embora cientes de que reificam concepções de sexo binário).

2 Vale lembrar a expressão popular inglesa "the West and the rest", cuja tradução para o português seria "o Ocidente e o resto" referindo-se à polaridade "entre o Ocidente - civilizado, adiantado, desenvolvido, bom - e o resto - selvagem, atrasado, subdesenvolvido, ruim" (Costa, 2006).

3 Segundo Isabelle Stengers (2011), os modernos definem-se a si mesmos como aqueles que teriam logrado o abandono das ilusões e das crenças. 
erro de nossos antepassados!" - convocava o professor ou a professora. "Os evolucionistas são como Nós! Felizmente foram criticados, mas não sejamos tão duros com eles. Eles estão mortos, são gente de outro tempo. Foram importantes para o nascimento da disciplina”. Para superar essa primeira etapa, era crucial perceber que os grupos sociais a que pertenciam os pais fundadores da antropologia não eram melhores que os dos iroqueses, lícios ou trobriandeses, e que as instituições dos primeiros não eram as únicas que faziam sentido.

Sim, as instituições dos Outros também funcionam. O funcionalismo se ergueu sob esta bandeira. Depois do funcionalismo, as aulas introdutórias se tornavam um grande campo de demolição. Seguiam o ritmo da história: da década de 1960 em diante, a disciplina parecia recusar as premissas de seus pais fundadores, encontrando neles uma série infindável de vícios etnocêntricos. Tal recusa não veio de uma pulsão de paz, mas foi imposta a grito pelos movimentos sociais radicais, pela luta pelos direitos civis da população negra estadunidense, pela contracultura e pelo movimento feminista que trouxeram à tona as vozes de pessoas que, até então, se viam subjugadas à categoria de objetó

O colonialismo e o imperialismo passaram a ser sistematicamente denunciados, colocando em xeque os pressupostos da cultura burguesa que marcavam a produção do conhecimento antropológico (Asad, 1973; Hymes, 1974). Ganhou força uma crítica abertamente autorreflexiva das práticas e políticas da representação do Outro nas quais se assenta a disciplina. Essa crítica foi protagonizada por vozes vindas não do "Nós antropológico", mas das pessoas que até então eram taxadas de Outras. A crítica potente reverberou no tempo e no espaço, sendo levada adiante por trabalhos feministas e pós-coloniais, pela antropologia pós-social e também pelos textos decoloniais. Tal crítica de cunho autorreflexivo, como dito, vai assim ocupando o cerne da disciplina e reclama o mesmo problema reiterado: o cânone antropológico continua logrando reproduzir seu cerne etnocêntrico.

Vale lembrar aqui o papel central de intelectuais pertencentes a grupos historicamente marginalizados, como Lélia Gonzalez, Bell Hooks, María Lugones, Yuderkis Miñoso, Luciana Ballestrin, Adelia Miglievich Ribeiro, Archie Mafeje e Morgan Ndlovu. Tais intelectuais denunciaram a forma como a suposta neutralidade científica é ancorada em uma ideia de ciência e de conhecimento que emerge da modernidade branca, ocidental e masculina, servindo como padrão à antropologia canônica e suas escolas. Nas palavras de Donna Haraway (1995: 07), traduzidas por Mariza Corrêa, a ciência "constitui uma espécie de conspiração invisível de cientistas e filósofos masculinistas, dotados de bolsas de pesquisa e de laboratórios".

De fato, historicamente, as formas de aprender e ensinar antropologia compõem e reforçam estruturas conceituais e epistemológicas arraigadas aos grilhões do pensamento colonial, cujos padrões eurocentrados se mostram capazes de universalizar o entendimento sobre a ciência e o conhecimento e, nesse bojo, sobre a disciplina. Em contraste, as imagens de ciência e de conhecimento que intelectuais pertencentes a grupos historicamente marginalizados projetam, apontam para o fato de que os processos de produção conhecimento se dão através das relações estabelecidas entre as pessoas envolvidas, sejam elas humanas ou não-humanas. Subvertem, assim, as rígidas relações de poder entre modalida-

4 A expressão "Os Outros respondem" - tradução livre de "The Others speak back" (Dewulf, 2006: 132) - designava o fato de aquelas pessoas, que desde o início do colonialismo tinham sido condenadas à passividade do outro, tomarem a palavra. 
des distintas de conhecimento e entre as pessoas envolvidas nas práticas de aprendizagem. Para tal, a própria forma como o conhecimento antropológico é produzido se ancora em relações de pesquisa pautadas em princípios absolutamente distintos 5 .

Em diálogo com essas vozes críticas, defendemos a necessidade de que estas reflexões sejam operacionalizadas não apenas nas pesquisas de campo ou nas salas de aula da pós-graduação, mas em cada curso, seja na formação de futuras antropólogas e antropólogos, seja nas matérias introdutórias para estudantes de outras áreas. Embora essas críticas constem como um importante capítulo da história da disciplina, entendemos que elas não foram suficientemente incorporadas nas práticas de ensino. Tudo se passa, a nosso ver, como se a docência estivesse ainda estacionada na ideia de que a disciplina é uma espécie de "sociedade secreta": antropólogas e antropólogos aprendem e ensinam que Nós somos parte de uma disciplina com ancestrais cruéis, mas ainda que esta é nossa família; em oposição a Outros, que, por mais fascinantes que sejam, sempre permanecerão Outros. Antropólogas e antropólogos muitas vezes aprendem e ensinam que só se faz "antropologia de dentro" e que é preciso que as alunas e alunos identifiquem-se com os pais fundadores da disciplina, antes de criticá-los, a fim de aprender com os erros destes que seriam seus predecessores. Aprendem e ensinam que fazer antropologia - independente do que essa antropologia significa - é o que une, em potência, aos tão diferentes autores e autoras, professores e professoras, alunos e alunas, em oposição às pessoas que não fazem antropologia. A anedota que narramos acima sobre o ensino da antropologia buscou mostrar isso e, nas próximas seções, os casos que apresentaremos também visam mostrar como reverbera ainda nos dias de hoje o modo de ensinar ancorado na dualidade Nós versus Outros e na ideia de que a disciplina é uma espécie de seita.

\title{
Reificando a alteridade - "diga-nos como é ser o outro"
}

\begin{abstract}
Imaginemos uma ONG que implanta um programa de combate à gravidez na adolescência em um país como o Brasil. Em muitos aspectos a cultura e a sociedade dos brasileiros é diferente da nossa. De modo geral, é uma cultura mais sexualizada que a europeia ou a ocidental. Nós, antropólogos, temos que lidar com tais diferenças quando trabalhamos em ONGs como essa. Talvez Claudia possa nos ajudar neste ponto. Claudia, fale-nos um pouco sobre a cultura de vocês do Brasil. Pessoal, prestem atenção para aprendermos sobre as diferenças com as quais nós, antropólogos, temos que lidar ao trabalhar com outras culturas e sociedades.
\end{abstract}

Claudia era eu, uma das autoras deste texto. Eu já passara da metade do curso de graduação em Ciências Sociais que cursava em Minas Gerais, no Brasil, e estava na Itália para cumprir um semestre de intercâmbio na Universidade de Bolonha, em 2008. Foi apenas ao ser interpelada sobre a cultura e sociedade do Brasil que percebi pela primeira vez que eu não me enquadrava (ou eles, antropólogos e antropólogas italianos, não me enquadravam) no "Nós antropológico". Inversamente, eu era o Outro, ou um dos tantos Outros que constituem o objeto de estudo da disciplina antropológica: eu vinha do Bra-

5 Agradecemos a quem elaborou os pareceres anônimos por nos ajudarem a desenvolver este ponto. 
sil, não era ocidental como eles. Independentemente do que eu pensasse e dissesse, para eles eu não fazia parte daquele "nós antropólogos", mas sim daquela cultura outra, brasileira, irredutivelmente diferente.

Ao longo dos anos de formação no Brasil, lendo textos sobre as populações estudadas pela disciplina (os Kachin e Chan da Ásia, os Nuer e os Ndembu do continente africano, os Tikopia e os Iatumul do pacífico sul) e textos sobre o ocidente (isto é, o que a cultura hegemônica de matriz europeia convencionou chamar assim), colegas estudantes, professores, professoras e eu sempre nos incluímos no "Nós antropológico". Nunca problematizei minha inclusão automática nesse Nós. Penso inclusive que se tivesse um rompante inquisidor e me pusesse a questionar de que lado da oposição Nós versus Outros estaria, chegaria à conclusão de que eu certamente pertenceria ao "Nós antropológico", posto que fazia parte da minoria da população mundial que tem acesso à educação ocidental formalizada em instituições como escolas e universidades.

No intuito de estudar ou ensinar sobre pessoas e coletivos historicamente marginalizados, a disciplina antropológica muitas vezes reifica diferenças e silencia esses grupos como Outros, reforçando estruturas hegemônicas violentas que, como ela própria já mostrou, têm consequências severas para uma parcela importante da população mundial. Assim, quando o ensino se dá através de perguntas como a que meu professor me fez, a disciplina reifica a alteridade e nega às pessoas que são tratadas como outras o direito de definirem a si próprias.

De fato, apesar de ter crescido no Brasil, não sou oficialmente brasileira: não tenho direito à cidadania, nem ao voto no país. Nasci na Itália, filha de pais italianos, avós italianos e assim por diante, até onde minha família se recorda. A cada dois anos, passei os verões na terra natal. Em família, mesmo no Brasil, falamos italiano. A despeito de tudo isso, naquele dia em Bolonha, para meu professor e colegas, eu era brasileira, parte da "cultura e sociedade dos brasileiros" que precisava da ajuda de ONGs. Ao me perguntar sobre "a sociedade e a cultura de vocês do Brasil" e ao se dirigir às demais pessoas na sala convidando a elas (mas não a mim) a “aprendermos sobre as diferenças com as quais Nós, antropólogos, temos que lidar ao trabalhar com outras culturas e sociedades", meu professor e colegas explicitamente deixavam de me tratar como antropóloga, como sujeito, e passavam a me tratar como objeto: um objeto que não pensa, apenas espelha uma realidade.

Eu já conhecia o conceito do etnocentrismo e a literatura crítica pós-moderna, pós-colonial e feminista da segunda metade do século XX. Já tinha sido tratada com desdém por pessoas na Europa que não me consideravam tão branca como elas, ainda que no Brasil eu sempre tenha sido percebida como tal. O que me deixava atônita era que ali, naquela sala de aula, junto a pessoas que supostamente eram meus pares, eu não era nem antropóloga (ainda que em formação), nem italiana (embora meus documentos e história atestassem o contrário), porque eu vinha do Brasil.

A antropologia que converte grupos heterogêneos de alunas e alunos em Nós é a mesma que objetifica como outras as também heterogêneas pessoas com quem realiza pesquisa. No momento em que eu deixava de fazer parte da seita do "Nós antropológico", eu percebia a violência que é recusar a uma pessoa sua condição de agente, isto é, tomá-la como outra. Na época, a lição não me tocou enquanto professora, mas sem dúvidas influenciou minha trajetória enquanto pesquisadora. Não faltaram aportes teóricos para isso e eu os aprendi nas mesmas universidades que me converteram antropóloga: a 
palavra de ordem era "levar a sério o nativo" (Viveiros de Castro, 2002; Goldman, 2016; Holbraad \& Pedersen, 2017).

Isto implicava formular as questões de pesquisa junto às pessoas com quem se faz pesquisa, a partir de suas inquietações, debatendo com elas tais questões (Bongianino, 2018), e não simplesmente escutar o que elas têm a dizer e depois pensar sobre isso a sós, a despeito do que elas sentem, pensam e querem. Gosto de pensar que não foi a conversão inicial, mas a adesão a essa nova ética de pesquisa que me transformou de fato na antropóloga que hoje sou. De um jeito ou de outro, a violência daquela situação em Bolonha era um sintoma de que a forma como se convenciona introduzir a teoria antropológica em sala de aula não educa as pessoas enquanto antropólogas, mas as converte à seita do seleto grupo que integra o cânone da disciplina - o "Nós antropológico".

\section{Negando a alteridade - "para aprender antropologia você deve ser como nós"}

No início do ano de 2018, dez anos depois da experiência de Claudia em Bolonha, eu, Amanda, assumi a disciplina de socioantropologia no curso de Turismo da Universidade do Estado de Mato Grosso (Unemat), campus de Nova Xavantina ${ }^{6}$. Munida de uma literatura que acompanhara os primeiros passos da minha graduação, recomendei a leitura das primeiras páginas do livro de Tzvetan Todorov (1983), chamado A conquista da América: a questão do outro. A primeira frase do livro é: “[q] uero falar da descoberta que o eu faz do outro" (grifos originais). Na sala, comecei o mito de origem da disciplina antropológica pelos encontros das Grandes Navegações, conectando-os aos pais fundadores da antropologia, grandes demiurgos europeus e estadunidenses, que haviam se dedicado ao estudo dos "selvagens" - que era como chamavam, de maneira preconceituosa e equivocada, eu ponderava, naturalmente, as populações que estudavam.

Narrado o mito, retomando a discussão das páginas de Todorov, escrevi em letras maiúsculas no quadro "NÓS X OUTROS” e me pus a discorrer sobre os “encontros antropológicos". Minhas palavras ressoavam aquelas de minhas professoras(es) e, talvez, também as de suas professoras(es). O meu entusiasmo diante da aula não durou mais que um minuto. Os rostos de alunas e alunos se contorciam em minha direção. "Alguma pergunta?" - indaguei. Seus rostos em silêncio quase me tocavam com seus olhares de incompreensão. Finalmente, um aluno afrouxou a face e falou: "Mas o Nós é... nós (e descreveu um círculo no ar que incluía ele e demais alunas e alunos)? Nós e os índios? Ou você e... (apontando agora para mim e descrevendo um círculo entre eu e o quadro negro, como se me unisse a quaisquer outras pessoas a quem eu estaria me referindo)?”.

Foi apenas quando confrontada pelo aluno que me dei conta do impropério que eu havia proposto. Minhas palavras pressupunham ser possível instituir naquela aula um elo de continuidade entre os pais fundadores da disciplina, eu, doutora vinda de uma capital do sudeste do Brasil, e minhas (meus) alunas(os), composta por estudantes habitantes de um município repleto de indígenas no interior do

6 Assiduamente frequentado por indígenas da etnia Xavante, o município de Nova Xavantina tem aproximadamente 20.000 habitantes e cresce a passos lentos em relação às cidades do entorno, grandes produtoras de gado e soja para exportação. 
estado de Mato Grosso. Para piorar, tal continuidade era proposta em contraposição a um universo objetificado de Outros que incluía toda a variedade dos povos indígenas, apesar de haver, na sala ao lado, um aluno da etnia Xavante cursando a quarta fase do curso de Biologia.

Os primeiros anos de minha graduação já estavam distantes e, como tantas pessoas formadas como antropólogas no Brasil, minhas experiências de pesquisa tinham sido pautadas em princípios radicalmente distintos daquela separação que eu propunha em sala de aula como alicerce do pensamento antropológico (Horta, 2018, 2020). Em campo, fazer antropologia era aprender com as pessoas com quem eu me relacionava. $\mathrm{Na}$ sala de aula, porém, a antropologia enquanto experiência de aprendizagem conjunta (Ingold, 2016) cedia lugar a uma noção de conhecimento objetificada no encadeamento de conteúdos que pretendia cooptar estudantes - a despeito de quem fossem e a despeito dos seus modos próprios de conhecer -, para que pudessem ver o mundo “à maneira da antropologia”, isto é, à maneira canônica dos pais fundadores da disciplina.

O que me autorizava a postular, em sala de aula, tal continuidade, era o fato de eu ter sido ensinada assim. Aluna da mesma universidade e no mesmo período em que estudou Claudia, dizia-se de Nós e de Outros dentro das salas de aula sem muito questionamento. Pensando retrospectivamente, porém, imagino que é altamente improvável que, em uma turma de 40 pessoas de uma grande universidade, fôssemos -Claudia e eu, colegas, docentes - todos iguais.

Na sala de aula da Unemat, eu via que criar o "Nós antropológico", apagando a diferença entre tais intelectuais, eu e cada discente, era um ato de violência. Antes disso, só o que eu percebia nesta comunhão forçosa era um ato de relação, de parentesco, de inclusão. Mas negar a diferença é também uma forma de dizer que o que é válido em ti é aquilo que coincide comigo, que nossas demandas são as mesmas e que, por isso, como formulou Zoe Todd (2015), "suas preocupações são inválidas". Dizer de Nós apagava por completo a presença de minhas (meus) alunas(os) enquanto sujeitos históricos e sociais e apagava também a subjetividade das pessoas indígenas com quem, a título de exemplo, eu nos contrastava - pessoas com quem quase todos e todas nós ali tínhamos algum tipo de convivência diária $^{7}$. Naquele dia, tal como o professor havia feito com Claudia na Bolonha de 2008, eu negava a minhas (meus) alunas(os) o direito e a possibilidade de definirem a si mesmos.

\section{A democratização das universidades brasileiras}

Até pouco tempo, no Brasil, o acesso ao Ensino Superior era restrito à elite, majoritariamente branca, dos estados e cidades mais ricos do país (Silva, 2015; Fernandes, 2016; Oliveira, 2019). Nas últimas três décadas, porém, este quadro começou a mudar. Por um lado, a política de cotas (raciais, étnicas, socioeconômicas e para pessoas com deficiência) e o alargamento do Fundo de Financiamento Estudantil (Fies) levaram para dentro das universidades pessoas que se viam excluídas desse espaço. Por outro lado, o Programa de Apoio a Planos de Reestruturação e Expansão das Universidades Federais (Reuni) abriu instituições de ensino superior fora dos grandes centros econômicos - a exemplo da

7 Tal convivência é marcada por forte preconceito (cf. Oliveira, 2010). Ainda assim, as pessoas não-indígenas em Nova Xavantina lidam com a presença constante de indígenas xavante, tornando-se muito difícil inviabilizá-la em seus repertórios de relações sociais. 
Universidade Federal do Recôncavo Baiano e da Universidade Federal do Oeste do Pará -, empregando docentes e atendendo à demanda regional por um Ensino Superior inclusivo e de qualidade.

A pesquisa no Brasil se transformou com este novo cenário, com mudanças nas agendas de pesquisa, na definição de prioridades e na produção do conhecimento acadêmico (Guarnieri \& Melo-Silva, 2017). Mais do que isso, a presença nas universidades de pessoas que se recusam a ser homogeneizadas em rubricas como "brancos de classe média com acesso ao Ensino Superior" vem levando também ao questionamento de velhos hábitos da docência. Práticas antigas e cômodas passaram a ter de se justificar, encontrando maior resistência pela presença pensante e pela voz ativa dessas pessoas que ocupam a posição de alunas - e que, formadas, já ocupam a posição de professoras, contra a resistência do cânone disciplinar. Se assumirmos que educar é muito mais que treinar o desempenho de determinadas destrezas e que ensinar não é transferir conhecimento, mas sim propiciar as condições para sua produção conjunta (Freire [1970] 2003; 1996), precisamos reconhecer que qualquer mudança no perfil das pessoas envolvidas (alunas e professoras) transforma, sem sombra de dúvidas, a aula que poderá, ali, acontecer.

A democratização do acesso às universidades destaca a necessidade de repensar a docência. Este é um movimento mandatório em todas as áreas e disciplinas, certamente, mas a disciplina antropológica tem um lugar fulcral neste universo. Isso porque ela tem se esforçado para abandonar um seu discurso sobre as populações (leia-se sobre as pessoas que pertencem ao coletivo com o qual a pesquisadora ou o pesquisador não se identifica), em prol da produção de um conhecimento colaborativo, oriundo da relação entre as pessoas envolvidas nas práticas de pesquisa.

Não por acaso, este movimento parece ganhar força justamente quando trabalhos antropológicos e de áreas afins, produzidos por pessoas que costumavam se ver excluídas destes espaços de produção de conhecimento, têm se avolumado e ganhado visibilidade no mundo acadêmico (Milanez et al., 2019; Archibald Q'um Q'um Xiiem et al., 2019; Mbembe, 2018; Santos, 2015; TallBear, 2015). Contudo, há poucos estudos e cursos sobre os impactos dessas transformações na docência e há um esforço ainda menor para a coletivização dessas transformações. Como afirmam Guilhermo Vega Sanabria e Luiz Fernando Dias Duarte (2019: 19), novas estratégias docentes são "felizmente cada vez mais frequente(s), mas infelizmente quase sempre improvisada(s)”. Contribuir e convidar a(o) leitora (leitor) para contribuir também para sanar esta lacuna é um dos objetivos do presente artigo.

No cenário atual da Educação Superior brasileira, torna-se cada vez mais difícil condicionar o ensino de qualquer disciplina ao postulado da identificação entre docentes e discentes. Não que as(os) muitas(os) alunas(os), professoras(es) fossem, antes, iguais - e que agora não sejam mais. O ponto é que, uma vez desvelado o fato de que jamais foram iguais, não é possível vela-lo outra vez. Não existe um Nós que se sustente em sala de aula, como mostram os relatos pessoais acima. Mais do que isso, esse Nós nunca existiu. Nesse sentido, as exclusões de gênero, de raça, de etnia, de classe, de pessoas com deficiência, dentre tantas outras que atravessam os meios acadêmicos e que são perpetradas pelas duas estratégias que intitularam os relatos de nossas experiências acadêmicas, isto é, a reificação da alteridade e a negação da alteridade, parecem ter um papel significativo na reprodução contínua das desigualdades 
e violências que caracterizam o cânone normativo da antropologia ${ }^{8}$. Como muitas(os) autoras(es) já mostraram, os espaços privilegiados de produção e ensino de conhecimento antropológico seguem sendo, em todo o mundo, dominados por homens brancos da classe média escolarizada (Chua \& Mathur, 2018).

A inclusão que condiz com os avanços teóricos da disciplina não pode se dar nos termos do grupo que detém o poder econômico, social ou político, mas deve ser conduzida necessariamente da maneira que interessa às pessoas incluídas, abrindo espaço para a possibilidade de subversão do que o cânone normativo tende a impor sobre a disciplina. Nesse processo produtivo e transformador que inclui, sem impor a homogeneização, note-se, nada impede que as pessoas incluídas acessem domínios que tendiam a ser considerados marcas exclusivas do Nós, como o dinheiro, a educação formal ocidental, o cristianismo, a internet, a medicina moderna, as caminhonetes, as academias de ginástica ou quaisquer outras dimensões e espaços existenciais.

Reconhecer a diversidade que compõe a sociedade - destacadamente a brasileira - e, ainda que em níveis muitos menores e sub representados, compõe hoje também as salas de aula, não é, em nenhuma instância, reificar a alteridade. Dizemos aqui de uma alteridade "em presença", em relação e, portanto, uma alteridade que não se pode isolar em oposição a um mundo moderno fatalmente solipsista aglutinado sob a égide de um nebuloso Nós e oposto ao universo igualmente nebuloso dos Outros. Reconhecer a diversidade também não é, de forma alguma, a negação da alteridade, num projeto que abraça a todas as pessoas numa igualdade sufocante, cujos termos são definidos por aquelas com maior poder e maior voz. Em ambos os casos, o que se passa é a imposição da dualidade Nós versus Outros, que em qualquer de suas atualizações acaba por prescrever categorias avessas à produção de conhecimento antropológico, seja em pesquisa ou ensino. Reconhecer a diversidade implica relacionar-se com ela por um enquadramento distinto ao da oposição que há décadas molda a estratégia de ensino de introdução à teoria antropológica.

A proposta aqui é a seguinte. Se a disciplina antropológica tem buscado abrir mão da prática de objetificação das pessoas com quem realiza pesquisa - recusando-se à reificação dessas pessoas como outras e acolhendo suas múltiplas vozes e demandas em busca de formas de produzir conhecimento com elas e não sobre elas -, cabe ainda abrir mão da conversão de nossas alunas e alunos ao "Nós antropológico". Tal aposta é essencial para que seja possível produzir, também em sala de aula, conhecimentos colaborativos, através do engajamento entre modos distintos de agir e de conhecer. Essa aposta corresponde a um caminho de ensino e aprendizagem no qual, ao invés de converter à seita (e às culpas do "Nós antropológico") para depois libertar o pensamento que estudantes têm sobre a disciplina, são rechaçadas atitudes que contribuem para a conversão primeira. Para tal, é preciso olhar a literatura com novos olhos e ensinar as pessoas em sala de aula - quer sejam futuras antropólogas, quer não - a olhar para a literatura também deste modo.

8 O cânone normativo da antropologia se refere ao que Ribeiro e Escobar (2008) chamaram antropologia hegemônica, um "conjunto de formações discursivas e práticas institucionais associadas com a normalização da antropologia acadêmica levada a cabo principalmente nos Estados Unidos, o Reino Unido e a França”" (tradução nossa). Ver também Restrepo e Escobar (2004; 2005). 
Como mostraram Grünewald e Benites (2017), ecoando Wagner (2010 [1981]), por muito tempo a disciplina antropológica se atribuiu a tarefa de investigar aquilo que artificiosamente atribuiu aos Outros e chamou, por sua própria conta, de 'cultura. "Mas nesse caso, e para todos os efeitos apenas uma dessas 'culturas' é tida como capaz de reflexionar sobre essa relatividade. E esta é, justamente, aquela de onde vem, primordialmente, os antropólogos" (Grünewald \& Benites, 2017: 105). Esse argumento não é mais, porém, unanimidade, quão menos entre as pessoas que não se identificam com o cânone da antropologia. Por isso, rejeitamos práticas de ensino que proponham qualquer tipo de identificação com os pais fundadores coloniais da disciplina. É preciso lê-los e dialogar com eles, sem, por isso, identificar-se com o "Nós antropológico". Para tanto, argumentamos que é preciso destacar a dimensão propositiva da descolonização, de modo que não seja preciso pressupor a violência colonial para apenas então lutar contra ela. Nesse sentido, há muito para aprender com o movimento indígena.

\section{Renascimento indígena}

Ao longo da década de 2010, a indicação de trabalhos de artistas indígenas para prêmios de alto prestígio trouxe à tona o que a mídia internacional anunciou como um "renascimento indígena". $\mathrm{O}$ mundo todo parece acompanhar, hoje, a produção indígena nas artes plásticas (como o projeto Mira! Artes Visuais Contemporâneas dos Povos Indígenas, discutido por Almeida, 2014), na literatura (a exemplo de Kopenawa \& Albert, 2010; 2013; 2015), na música (como o disco premiado de Jeremy Dutcher e o rap indígena Guarani e Kaiowa, conforme analisam Oliveira, 2016 e Guilherme, 2017) e na academia (Mehinaku, 2010; Outakoski, 2015; Simpson, 2014; TallBear, 2015; Todd, 2014, 2015; Corrêa Xakriabá, 2018). Na disciplina antropológica, por sua vez, tal renascimento é tido como uma dimensão de um fenômeno mais amplo ligado à autodeterminação política destes povos (Clifford, 2013).

O fenômeno se vê nas redes sociais através de hashtags que se tornaram tendência nas Américas, como \#dontrushchallenge e \#passthebrushchallenge. Nestas postagens, indígenas aparecem com roupas tipicamente modernas e, em seguida, por uma montagem do vídeo, ressurgem com seus trajes tradicionais (Localish, 2020; Sururás do Tapajós, 2020. A ampla difusão destes vídeos manifesta o reconhecimento da autodeterminação étnica como motivo de orgulho e admiração para indígenas e não indígenas. Vê-se também o fenômeno na indicação do Cacique Raoni Metuktire, do povo kayapó, ao prêmio Nobel da paz nos anos de 2019 e $2020^{\circ}$. A presença contundente de indígenas nas Conferências Mundiais do Clima realizadas pela Organização das Nações Unidas (ONU) também reforçou o protagonismo indígena e sua crescente participação enquanto atores globais nos debates sobre a urgência da preservação ambiental.

Falamos de um fenômeno global, de modo que em cada povo, em cada comunidade, ele se apresenta, obviamente, com seus contornos próprios. Além disso, é importante destacar que as raízes do renascimento indígena remontam aos anos 1980. À época, questões relacionadas ao meio ambiente e aos

9 No lançamento da campanha de 2019, a Fundação Darcy Ribeiro destacou que Raoni "dedicou sua vida à luta pelos direitos dos indígenas e pela preservação da Amazônia” (Vicente, 2019). O vencedor, no entanto, foi Abiy Ahmed Ali, primeiro-ministro da Etiópia. 
direitos das minorias étnicas começavam a romper as fronteiras nacionais e ONGs passavam a apoiar projetos que combinavam o desenvolvimento social dos povos tradicionais com a preservação ambiental. No Brasil, a década de 1980 foi marcada também pela virada demográfica dos povos indígenas, que até pouco antes julgava-se estarem fadados à extinção (Ribeiro, 1977: 445). Igualmente notáveis são os casos de grupos no Caribe e na Tasmânia, exemplos clássicos de povos que teriam desaparecido com o genocídio colonial, mas que seguem vivos, ativos e resistentes, segundo mostram trabalhos recentes (Forte, 2005, 2006; Roche et al., 2018). De fato, o crescimento populacional de minorias étnicas é uma tendência mundial associada ao renascimento indígena e às mudanças políticas e econômicas trazidas pelo capitalismo tardio, sobretudo nas últimas décadas do século XX.

Apesar da grave ofensiva anti-indígena movida pelo interesse econômico de setores ligados ao agronegócio, à mineração, etc. (Bonilla \& Capiberibe, 2015), os povos indígenas no Brasil não apenas resistem: eles também florescem. O lugar de fala por eles ocupado hoje, com muita luta, não tem se limitado a denunciar as inumeráveis violências que sofrem, nem em lutar pela sua continuidade física em face ao ideal de progresso que comanda o país. Mais do que reagir, os povos indígenas no Brasil colocam em cena o mundo que habitam, suas formas produtivas - e não destrutivas, como as do discurso desenvolvimentista - de existir junto ao que pessoas partidárias da cultura hegemônica de matriz europeia convencionaram chamar natureza.

Ailton Krenak (2020) diz "já vi pessoas ridicularizando: 'ele conversa com árvore, abraça árvore, conversa com o rio, abraça a montanha' como se isso fosse uma espécie de alienação”. Mais do que negar a chacota que lhe fazem, o autor afirma categoricamente: isso não é alienação, "essa é a minha experiência de vida". Krenak vive à beira do Rio Doce, vítima do rompimento da barragem de rejeitos da Samarco Mineração. Estabelecer uma relação com o rio, seja pela escuta, pelo desfrute, pelo afeto, parece ser uma de suas "Ideias para adiar o fim do mundo", parafraseando o título de outra publicação sua (Krenak, 2019). Este exemplo evidencia a dimensão propositiva, dinâmica e criativa do renascimento indígena, que se orienta para a construção do presente, sem por isso minimizar as violências do passado.

O renascimento indígena, assim, instiga a imaginar um projeto de docência liberto da tarefa de identificar alunas e alunos a intelectuais de outrora, com suas culpas coloniais, para depois louvar a crítica e o arrependimento diante dos tantos atos de violência que acompanham o desenvolvimento da disciplina. É possível operar uma descolonização que reconhece o passado, e que ao mesmo tempo apresenta uma agenda propositiva - como argumentamos aqui. Apresentar os pais fundadores da antropologia sem ter que converter discentes requer quatro certezas: 1) a de que a produção do conhecimento antropológico no presente não precisa assumir as culpas de certas pessoas e instituições do passado para se sustentar; 2) a de que antropólogas(os) não precisam se identificar com quem protagonizou os atos coloniais e imperialistas do início do século XX (e além); 3 ) a certeza também de que tais violências não serão esquecidas e que nada há de tirar a culpa ${ }^{10}$ de quem as cometeu; 4) e, por fim, a de que as pessoas não se fazem menos antropólogas, por não se identificarem com o "Nós antropológico". A disciplina precisa narrar suas histórias sem dividir o mundo - a sala de aula - em equipes de pessoas

10 Sobre a imprescritibilidade e irreversibilidade da culpa nos crimes contra a humanidade ou crimes de genocídio ver Ricoeur (2007). 
empoderadas supostamente iguais, em oposição a pessoas de diferença irredutível, cujas vozes são historicamente silenciadas. Esta narrativa divisionista reifica o ato de calar-lhes a voz.

A democratização das universidades brasileiras, o renascimento indígena e os relatos pessoais apresentados acima se alinham com trabalhos publicados, teses e dissertações produzidas nas últimas décadas que se apropriam do passado colonizador da disciplina antropológica como potência de vida e liberdade. Juntos, todos estes movimentos mostram que, mais do que nunca, é hora de garantir que os modos de ensinar e aprender se tornem mais condizentes com os desenvolvimentos críticos da disciplina. Embora esses movimentos já venham produzindo efeitos importantes nas práticas de pesquisa, nós, Amanda e Claudia, argumentamos que seus efeitos ainda não foram plenamente incorporados às práticas de ensino. A agenda propositiva de resistência que caracteriza o Renascimento indígena inspira a pensar também modos de ensinar e aprender antropologias, no plural, que não precisem reproduzir a violência para lutar contra ela.

\section{Para aprender e ensinar antropologias}

Enfatizar a dimensão propositiva dos discursos de resistência: esta é uma questão urgente para uma agenda de atuação antropológica voltada para o combate dos processos de violência, dominação e exploração que impregnam suas raízes político-epistemológicas e suas práticas de ensino tradicionais. Conforme aprendemos nos cursos introdutórios e mencionamos na primeira parte deste artigo, a crítica é intrínseca à história da disciplina que, a partir dos anos de 1960, passou a responder com a devida atenção aos gritos das pessoas que eram usualmente tidas como seu objeto de estudo, que refutavam a suposta neutralidade da ciência e que combatiam o ocultamento dos corpos e das vozes de populações historicamente marginalizadas. Uma destas pessoas foi Archie Mafeje, antropólogo sul-africano que confrontava a teoria antropológica pós-moderna, argumentando que faltava a ela reconhecer o papel das próprias comunidades nativas na descolonização do pensamento antropológico (Mafeje, 2001).

Mas a obra de Mafeje traz mais que a denúncia das práticas coloniais da antropologia pós-moderna, centradas na diferença irredutível entre quem traduz a experiência (dos Outros) ao texto, e quem a vive. Através do conceito de africanidade, o autor opera a recusa da colonização, para trazer à tona o aspecto positivo e propositivo da "africanidade" e da contribuição epistemológica africana (Mafeje, 2008). Assim, Archie Mafeje propõe a negação da negação, isto é: negar que às populações africanas seja negada a agência sobre suas existências. Há aqui uma ressonância entre o conceito de "africanidade" e o renascimento indígena que apresentamos na seção anterior, na medida em que ambos configuram resistências propositivas e criativas.

No mesmo sentido, ao invés de desconstruir ou desconverter alunas e alunos, propomos a negação da negação da voz às minorias - sejam elas de raça, de etnia, de classe, de condição do corpo, do lugar de moradia, da língua falada. Propomos a negação da conversão mesma à seita do "Nós antropológico", pois, ainda que momentânea, tal conversão reifica a colonização primeira que impregna as raízes da disciplina. É possível falar do passado sem para isso replicá-lo (sequer por um momento) no presente. $\mathrm{O}$ movimento de Mafeje, que tanto se alinha às nossas palavras e intenções aqui, é propositivo 
e combativo: uma ontologia pautada na constatação de que o mundo a todo tempo se transforma e de que não existe nenhuma diferença a priori capaz de separar as pessoas entre Nós e Outros, entre pesquisadoras e pessoas com quem realizam pesquisas - nem entre alunas e professoras, acrescentaríamos.

Retomar o argumento de Archie Mafeje à luz dos desenvolvimentos críticos da disciplina implica atuar ativamente para a inclusão transformadora e para a crítica propositiva que interessa a nós, neste texto e em nossa atuação como antropólogas. Para este autor e para outras vozes que nele ecoam, a etnografia deveria servir como meio de modificar as formas acadêmicas e ordinárias de conhecer e, portanto, de transformar a capacidade da disciplina de intervir e alterar o status quo (Borges et al., 2015). Nesse artigo, argumentamos que este movimento deve ser instituído também, cada vez mais, nas salas de aula, levando professoras e professores a se recusarem a apresentar a disciplina antropológica como um jogo no qual é preciso necessariamente escolher o seu time: o time do Nós ou o time dos Outros.

Há antropólogas e antropólogos que afirmam que o Nós é uma metáfora necessária, que serve para se referir àquilo que é dado, estabelecido como norma em uma sociedade. Em contraponto, entendemos que recusar o Nós, ainda que metafórico, implica também recusar a rigidez da matriz epistemológica canônica, assumindo que ela é o tempo todo subvertida por quem dela se apropria. $\mathrm{O}$ cânone não parece ter interesse na abertura do Nós a outras formas de pensar, mas esta abertura não é uma escolha, ela acontece enquanto escrevemos estas linhas - e acontece enquanto vocês as leem -, a custo de grito, suor e sangue das pessoas muitas vezes chamadas de minorias, mas que na prática, numericamente, constituem a maioria esmagadora da população mundial.

Nesse sentido, a proposição de Dipesh Chakrabarty (2000) de "provincializar” a Europa é iluminadora. Ela implica localizar historicamente o pensamento e a experiência europeus, de modo que docentes não apresentem a disciplina como coincidindo com aquela produzida por pessoas da Europa. Concordamos que realizar este exercício é essencial, sobretudo quando falamos de salas de aula onde os privilégios tendem a inclinar discentes a se perceberem como social, cultural, racial e economicamente superiores.

É preciso também recusar a apresentar a disciplina antropológica como coincidindo com aquela produzida por pessoas que, fora da Europa, protagonizam a cultura de matriz europeia (leiase pessoas que, em qualquer local do mundo, são privilegiadas de acordo com padrões hegemônicos globalizados vinculados à branquitude e ao capitalismo). Antropólogas e antropólogos formam hoje uma comunidade transnacional e aberta, não um séquito restrito. Existem inúmeras pessoas - aquelas com quem se realiza pesquisas, bem como alunas, professoras e pesquisadoras - que lutam pela simetria destas diferentes posições e pelo reconhecimento de que todas podem aprender umas com as outras.

Conforme tantas outras críticas já ressaltaram, porém, não basta apenas desprovincializar, pois a dominação geopolítica é apenas uma das tantas dimensões que abafam as liberdades das populações historicamente marginalizadas. Sendo assim, é preciso atentar-se para as particularidades de cada sala de aula, de cada sujeito presente, como antropólogas e antropólogos têm mostrado ser possível fazer em campo. Lembremos a bela formulação de Tim Ingold (2016: 407) para quem a antropologia seria uma "prática de educação". Educação, aqui, tem o sentido forte que ressoa Paulo Freire (2003 [1970], 1996): uma educação que não pretende transferir conhecimentos de uma pessoa a outra, mas produzir 
conhecimentos e transformar os sujeitos (que enquanto tal são sempre históricos e sociais) envolvidos no ato de os produzir.

Junto com Ingold, entendemos que é preciso fazer antropologias de múltiplas formas em campo, compartilhando a aprendizagem entre as pessoas envolvidas nas práticas de pesquisa; e que é preciso também fazer múltiplas antropologias em sala de aula, pela colaboração ativa entre professoras e professores, alunas e alunos, em ordem de levar adiante, na prática, a coprodução de conhecimento à qual se propõem, hoje, as antropologias engajadas em minimizar assimetrias e pluralizar saberes, estruturas e caminhos

Ao buscar consolidar essa transformação, é fundamental que as salas de aulas, em qualquer nível acadêmico e contexto didático, tragam para o primeiro plano as ditas "antropologias sem história" (Krotz, 1997: 240). A expressão de Krotz é abertamente irônica pois se refere às antropologias historicamente caladas e invisibilizadas sob as cortinas do cânone hegemônico, aquele que repetido nas salas de aula de muitos cantos do mundo - de matriz europeia. Falar em antropologias é uma forma de começar a abrir os caminhos para o reconhecimento da pluralidade de formas de produzir conhecimento conjuntamente e para a variedade de efeitos - vidas, destinos, produtos, ideias, movimentos - que estes saberes podem engendrar.

O que queremos dizer com tudo isso, na prática? Queremos dizer que é possível um projeto de ensino liberto da tarefa de criar uma identificação entre os intelectuais fundadores da disciplina antropológica e estudantes do presente. Para tal, é preciso localizar os debates de cada antropologia no tempo e no espaço. É preciso discutir com alunas e alunos quais são as imagens de antropologias que se depreendem de cada autora e autor, de cada obra, de cada texto, no limite. Afinal, bem sabemos, uma mesma autora ou um mesmo autor pode ser fonte de diferentes antropologias, criando em sua obra diferentes imagens de humanidade, ainda que por extensão - e é preciso enfatizar esse ponto em sala de aula.

Tudo isso quer dizer que as salas de aula devem incluir um debate sobre os modos como essas noções de antropologias e de humanidades condicionam a prática da disciplina (em campo, em sala de aula, no gabinete ou em qualquer lugar) e a relação com os saberes nativos. Abordar esses pontos nas ementas das disciplinas e estar aberta e aberto para ouvir as alunas e alunos, transformando a cada instante os programas didáticos a partir desta escuta, é crucial para transformar as salas de aula em espaços onde as pessoas possam se engajar umas com as outras, e com a literatura, a partir de seus próprios lugares históricos e sociais.

Nosso argumento é que os conteúdos apresentados não devem reproduzir outras aulas, ainda que bem sucedidas, dadas em outros contextos, com outras professoras e professoras, alunas e alunos. O foco deve ser na relação que as pessoas estabelecem com os conteúdos a partir de seus próprios lugares históricos e sociais, para que possam produzir conhecimentos juntas, da mesma forma como as antropólogas e os antropólogos fazem em campo, junto das pessoas com quem realizam pesquisas.

Por exemplo, em 2008, na sala de aula em Bolonha, o professor poderia ter convidado as alunas e os alunos a pensar sobre quem são as pessoas chamadas de outras. Assim, poderia ter perguntado a todas as pessoas ali presentes - e não apenas a uma delas que fora pressuposta como interlocutora pri- 
vilegiada, no caso eu, Claudia - sobre o que sabiam sobre a cultura e a sociedade das populações em que atuam ONGs. Com base na escuta de alunas e alunos, o professor poderia ter discutido os estudos realizados em determinadas periferias brasileiras, que apresentam a complexidade da vida travada ali, a história do surgimento dessas comunidades e os desejos, ansiedades e projetos de futuro das mesmas.

De maneira análoga, em 2018, na sala de aula em Nova Xavantina que se iniciava com um texto de Todorov, a professora poderia ter conduzido a aula através das seguintes perguntas: quem são essas pessoas a quem Todorov chama de outras? O que sabemos sobre elas através destes textos? Qual estatuto de humanidade é concedido a elas e o que isto implica em termos de dignidade, de autonomia, de reconhecimento de seu direito de decidir sobre seus próprios destinos? Questões como essas trazem para o primeiro plano a humanidade das pessoas a quem a antropologia canônica muitas vezes chama de outras.

Nas salas de aula, ao abordar os pioneiros da disciplina e autoras e autores nativos, historicamente excluídos dos principais espaços de produção e de difusão de conhecimento antropológico, docentes poderiam debater as relações entre as pessoas envolvidas na pesquisa antropológica. Poderiam também fazer perguntas sobre as relações de pesquisa em cada bibliografia analisada. Poderiam assim, com base na escuta, enfatizar as relações produtivas e criativas ou destrutivas e colonizadoras, bem como as relações de poder envolvidas na produção destes conhecimentos.

Professoras e professores convidam com frequência as alunas e os alunos a se imaginarem como pesquisadoras e pesquisadores em campo. Não seria interessante propor o exercício simétrico, no qual todas as pessoas na sala de aula se colocariam no lugar das populações sobre as quais as antropologias produzem conhecimento? Experimentar uma versão simulada da relação antropológica e ocupar suas diferentes posições pode contribuir para a humanização das pessoas envolvidas e para o reconhecimento das violências perpetradas pela objetificação das pessoas e do conhecimento, por exemplo, ao adotar dicotomias como Nós e Outros. Quão enriquecedor seria se estudantes da Universidade de Bolonha em 2008 tivessem sido convidadas(os) a imaginar uma ONG estrangeira que as tomasse como público-alvo? Ou ainda se discentes na Unemat, em 2018, tivessem sido convidadas(os) a imaginar uma pesquisa qualitativa realizada junto com elas próprias, vendo a potência de um trabalho antropológico colaborativo ganhar força em sua formação?

Seja na Universidade de Bolonha em 2008, seja na Unemat em 2018, seria possível desenvolver junto a estudantes questionamentos sobre qual a perspectiva de futuro projetada em cada obra. Ao abordar um programa didático que prevê a leitura dos pais fundadores da disciplina e de autoras(es) pertencentes a grupos historicamente marginalizados, é possível e positivo instigar a reflexão crítica sobre as perspectivas de futuro que, em cada caso, as antropologias localizadas projetam sobre as populações com as quais produzem conhecimento. Tais populações estão destinadas a um enquadramento evolucionista? A um desenvolvimentismo unidirecional capitalista e ocidental? À possibilidade de se recriar constantemente em seus próprios termos?

$\mathrm{Na}$ mesma medida em que certas pesquisas podem contribuir ou minar a emancipação e a autonomia de um coletivo, a forma de ensinar também pode ter consequências para o modo como as pessoas se relacionam com conhecimentos e projetos de vida que não coincidem com os seus. Questões 
como as elencadas acima permitem debater as condições de produção destes conhecimentos durante aquilo que a antropologia canônica convencionou chamar de "trabalho de campo" ou, ainda, em quaisquer outros lugares onde a aprendizagem colaborativa possa ser colocada em prática, como na sala de aula. Este projeto de docência é a proposta deste artigo para ajudar a transformar o modo como a disciplina é convencionalmente ensinada em sala de aula, permitindo a todas as pessoas aprender e ensinar antropologias específicas e localizadas.

\begin{abstract}
Amanda Horta é Doutora em Antropologia Social pelo Museu Nacional da Universidade Federal do Rio de Janeiro (MN/UFRJ) e pesquisadora do Laboratório de Alteridades da Universidade Federal de Ciências da Saúde de Porto Alegre (UFCSPA).
\end{abstract}

Claudia Bongianino é Doutora em Antropologia Social pelo Museu Nacional da Universidade Federal do Rio de Janeiro e atualmente atua na Fundação Renova. Também épesquisadora no Laboratório de Antropologia e História do Museu Nacional (LAH/MN/ UFRJ.

\title{
REFERÊNCIAS
}

Almeida, M. I. de. (2014). Mira! - Artes Visuais Contemporâneas dos Povos Indígenas. Introdução. Mundo Amazónico, 5, 185-188.

Archibald Q'um Q'um Xiiem; Archibald, J-A.; Lee-Morgan, J.; \& De Santolo, J. (2019). Decolonizing Research: Indigenous Storywork as Methodology. Zed Books.

Asad, T. (org.). (1973). Anthropology and the colonial encounter. London: Ithaca Press.

Bongianino, C. (2018). Deus e Outros parentes invisiveis (Tese de Doutorado). Museu Nacional, Universidade Federal do Rio de Janeiro, Rio de Janeiro.

Borges, A.; Costa, A.; Couto, G.; Cirne, M.; Lima, N.; Viana, T.; \& Paterniani, S. (2015). Pós-Antropologia: as críticas de Archie Mafeje ao conceito de alteridade e sua proposta de uma ontologia combativa. Sociedade e Estado, 30(2), 347-369. https://doi.org/10.1590/S0102-699220150002000005

Capiberibe, A. \& Bonilla, O. (2015). A ocupação do Congresso: contra o quê lutam os índios? Estudos Avançados, 29(83), 293-313. https://doi.org/10.1590/S0103-40142015000100014

Chakrabarty, D. (2000). Provincializing Europe. Postcolonial Thought and Historical Difference. Princeton, Princeton University Press. 
Chua, L., \& Mathur, N. (2018). Reimagining Alterity and Affinity in Anthropology. Front Cover. Oxford, New York: Berghahn Books.

Clifford, J. (2013). Becoming Indigenous in the Twenty-First Century. Cambridge, MA: Harvard University Press.

Collins, B.; Laws, M. C., \& Ntakirutimana, R. (2020). Becoming “Historically Marginalized Peoples": examining Twa perceptions of boundary shifting and re-categorization in post-genocide Rwanda. Ethnic and Racial Studies 44(4), 576-594. https://doi.org/10.1080/01419870.2020.1767798

Corrêa, M. (1997). Dona Heloisa e a pesquisa de campo. Revista de Antropologia, 40(1), 11-54. https://doi.org/10.1590/S0034-77011997000100002

Corrêa Xakriabá, C. N. (2018). O barro, o genipapo e o giz no fazer epistemológico de autoria Xakriabá: reativação da memória por uma educação territorializada. (Dissertação de Mestrado). Universidade de Brasília, Brasília.

Costa, S. (2006). Desprovincializando a sociologia: a contribuição pós-colonial. Revista Brasileira de Ciências Sociais, 21(60), 117-134. https://doi.org/10.1590/S0102-69092006000100007

Dewulf, J. (2006). Por vozes nunca dantes ouvidas: a viragem pós-colonial nas ciências humanas. In A. L. Amaral \& G. Cunha (orgs). Estudos em homenagem a Margarida Llosa (131-140). Porto: Universidade do Porto.

Fernandes, L. C. (2016). Cotistas e Não Cotistas: Qual o Desempenho dos Alunos do IFMT? (Dissertação de Mestrado). Universidade Federal de Pernambuco, Recife.

Forte, M. (2005). Ruins of Absence, Presence of Caribs: (Post)Colonial Representations of Aboriginality in Trinidad and Tobago. Miami: University of Florida Press.

Forte, M. (2006). 'Introduction: The dual absences of extinction and marginality - what difference does an indigenous presence make?' In Indigenous Resurgence in the Contemporary Caribbean: Amerind Survival and Revival (pp 1-18). New York: Peter Lange.

Freire, P. ([1970] 2003). Pedagogia do Oprimido. Rio de Janeiro: Edições Paz e Terra.

Freire, P. (1996). Pedagogia da autonomia: saberes necessários à prática educativa. São Paulo: Edições Paz Terra.

Geertz, C. (1978). A interpretação das culturas. Rio de Janeiro: Zahar.

Goldman, M. (2016). Mais alguma antropologia: ensaios de geografia do pensamento antropológico. São Paulo: Ponteio. 
Grünewald, L., \& Benites, A. C. (2017) Anti-equivalências. Sobre duas antropologias. Nanduty, 5(6), 103-118. https://doi.org/10.30612/nty.v5i6.6876

Guarnieri, F. V., \& Melo-Silva, L. L. (2017). Cotas Universitárias no Brasil: Análise de uma década de produção científica. Psicologia Escolar Educacional, 21(2), 183-193. https://doi.org/10.1590/21753539201702121100

Guilherme, J. C. (2017). A poética da luta: rap indígena entre os Kaiowá e Guarani em Mato Grosso do Sul. (Dissertação de mestrado). Programa de Pós-Graduação em Antropologia Social, Universidade Federal de Santa Catarina, Florianópolis.

Harari, Y. N. (2014). Sapiens: A brief history of humankind. Nova Iorque: Random House.

Haraway, D. (1995). Saberes localizados: a questão da ciência para o feminismo e o privilégio da perspectiva parcial. Cadernos Pagu, 5, 07-41. https://periodicos.sbu.unicamp.br/ojs/index.php/cadpagu/ article/view/1773

Holbraad, M., \& Pedersen, M. A. (2017). The Ontological Turn: An Anthropological Exposition. Cambridge: Cambridge University Press.

Horta, A. (2018). Relações indígenas na cidade de Canarana (MT). (Tese de Doutorado). Museu Nacional, Universidade Federal do Rio de Janeiro, Rio de Janeiro.

Horta, A. (2020). Oengman Menen: vê seu caminho. Apontamentos sobre a vida e as mortes das mulheres ikpeng. Brasília: Gráfica Movimento.

Hymes, D. (org.). (1974). Reinventing anthropology. New York: Vintage.

Ingold, T. (2016). "Chega de etnografia! A educação da atenção como propósito da antropologia”. Educação, 39(3), 404-411. https://doi.org/10.15448/1981-2582.2016.3.21690

Kopenawa, D., \& Albert, B. (2010). La chute du ciel. Paroles d'un chaman yanomani, Paris: Plon.

Kopenawa, D., \& Albert, B. (2013). The falling sky: words of a Yanomami shaman. Massachusets-London: Belknap Press.

Kopenawa, D., \& Albert, B. (2015). A queda do céu. Palavras de um xamã yanomami. São Paulo: Companhia das Letras.

Krenak, A. (2019). O amanhã não está à venda. São Paulo: Cia das Letras.

Krenak, A. (2020). Ideias para adiar o fim do mundo. São Paulo: Cia das Letras. 
Krotz, E. (1997). Anthropologies of the South: Their Rise, Their Silencing, Their Characteristics. Critique of Anthropology, 17(3), 237-351. https://doi.org/10.1177/0308275X9701700302

Localish. (2020) Native American Girls Transform into Traditional Clothing. Youtube, 20 de abril. Disponível em: https://www.youtube.com/watch?v=9Gaeuc7TsTc

Mafeje, A. (2001). Anthropology in post-independence Africa: end of an era and the problem of self definition. Nairobi: Heinrich Böll Foundation; Regional Office East and Horn of Africa.

Mafeje, A. (2008). Africanity: a combative ontology. Codesria Bulletin, 3-4, 106-110.

Maruyama, H., \& Kroik, Å. V. (2018). Indigenous Efflorescence. Beyond revitalization in Sapmi and Ainu Mosir. Camberra: ANU Press.

Mbembe, A. (2018). Necropolitica. São Paulo: n-1 Edições.

Mehinaku, M. (2010). Tetsualü: pluralismo de linguas e pessoas no Alto Xingu (Dissertação de mestrado). Programa de Pós-graduação em Antropologia Social, Museu Nacional, Universidade Federal do Rio de Janeiro, Rio de Janeiro.

Milanez, F., Sá, L. Krenak, A., Cruz, F. S. M., Ramos, E. U. \& Pataxó, G. S. (2019). Existência e diferença: O racismo contra os povos Indígenas. Revista Direito e Práxis 10(3). 2161-2181. https://doi. org/10.1590/2179-8966/2019/43886

Vicente, J. P. (2019). Quem é Raoni Metuktire, caiapó apontado como candidato ao Nobel da Paz. National Geographic. Disponível em: https://www.nationalgeographicbrasil.com/meio-ambiente/2019/10/quem-e-raoni-metuktire-caiapo-apontado-como-candidato-ao-nobel-da-paz Acesso: abr. 2020.

Oliveira. A. L. M. de. (2019). Educação Superior brasileira no início do século XXI: inclusão interrompida? (Tese de Doutorado). Universidade Estadual de Campinas, Campinas.

Oliveira, L. de. (2016). Bro Mc’s rap indígena: O pop e a constituição de fóruns cosmopolíticos na luta pela terra Guarani e Kaiowa. Revista eco pós. Cultura POP, 19(3), 199-220. https://revistaecopos.eco.ufrj.br/eco_pos/article/view/3790

Oliveira, N. A. de. (2010). Ser Xavante, morar e estudar na cidade: os Xavante em Nova Xavantina/ MT. Patrimônio e Memória, 10(2), 235-253.

Outakoski, H. (2015). Davvisámegielat čálamáhtu konteaksta [The context of North Sámi literacy]. Sámi diectalaš áigečála, 1, 29-59. 
Peirano, M. (2006). Um ponto de vista sobre o ensino da antropologia. In M. P. Grossi, A. Tassinari, \& C. Rial (orgs.). Ensino de antropologia no Brasil: formação, práticas disciplinares e além fronteiras (77-104). Blumenau: Nova Letra.

Restrepo, E., \& Escobar, A. (2004). Antropologías en el mundo. Jangwa Pana, (3), 110-131.

Restrepo, E., \& Escobar, A (2005). Other Anthropologies and Anthropology Otherwise: Steps to a World Anthropology Network. Critique of Anthropology, 25(2), 99-129. https://doi.org/10.1177/0308275X05053009

Ribeiro, D. (1977). Os Índios e a Civilização: a integração das populações indígenas no Brasi moderno. Rio de Janeiro: Vozes.

Ribeiro, G. L., \& Escobar, A. (2008). Antropologias del mundo. Transformaciones disciplinarias dentro de sistemas de poder. Popayán: Diseño Grafico e Impresiones.

Ricoeur, P. (2007). A memória, a história e o esquecimento. Campinas, SP: Editora Unicamp.

Santos, A. B. dos. (2015). Colonização, quilombos: modos e significações. Brasília: INCTI, UnB.

Silva, G. U. L. da. (2015). O desempenho e as cotas: o caso da UFSC. (Dissertação de Mestrado). Programa de Pós-graduação em Sociologia Política, Universidade Federal de Santa Catarina, Florianópolis.

Simpson, A. (2014). Mohauwk Interruptions. Political life across the borders of settler States. Durham and London: Duke Univertsity Press.

Stengers, I. (2011). Cosmopolitics II. Minneapolis: University of Minnesota Press.

Surarás do Tapajós. Challenge - Mulheres Indigenas. Youtube, 7 de abril de 2020. Disponível em: https://www.youtube.com/watch?v=h0aqs4D3e70

TallBear, K. (2015). Dossier: Theorizing Queer Inhumanisms: An Indigenous Reflection on Working Beyond the Human/Not Human. GLQ: A Journal of Lesbian and Gay Studies, 21(2-3), 230-235. Todd, Z. (2014). Indigenizing the Anthropocene. In H. Davis \& E. Turpin. (ed). Art in the Anthropocene: Encounters Among Aesthetics, Politics, Environment and Epistemology (pp. 241-254). London: Open Humanities Press.

Todd, Z. (2015). The We and Them of Anthropology. Savage Minds. May 16, 2015. Disponível em: https://savageminds.org/2015/05/16/the-we-and-them-of-anthropology. Acesso em: abr. 2020.

Todorov, T. (1983). A conquista da América: a questão do outro. São Paulo: Martins Fontes. 
Vega Sanabria, G., \& Dias Duarte, L. F. O ensino de Antropologia e a formação de antropólogos no Brasil hoje:de tema primordial a campo (possível) de pesquisa (antropológica). Revista Brasileira de Informação Bibliográfica em Ciências Sociais - BIB, 90(3), 1-31. https://doi.org/10.17666/ bib9010/2019

Viveiros de Castro, E. (2002). O nativo relativo. Mana, 8(1), 113-148. https://doi.org/10.1590/ S0104-93132002000100005

Wagner, R. (2010 [1981]). A invenção da cultura. São Paulo: Cosac Naify. 


\title{
PARA APRENDER E ENSINAR ANTROPOLOGIAS
}

Resumo: Este artigo explora relatos sobre experiências acadêmicas das autoras para refletir sobre formas de aprender e ensinar antropologias capazes de incorporar seu potencial reflexivo à prática docente. Em diálogo com autores e autoras que analisam criticamente as raízes coloniais da disciplina, argumentamos que o método de ensino ancorado na dualidade Nós versus Outros tende a produzir antropólogas e antropólogos identificadas com o Nós nessa dualidade e isso é politicamente perigoso. Realizada sobre o pano de fundo da democratização do acesso ao Ensino Superior no Brasil e do fenômeno do "renascimento indígena", a análise enfatiza o crescente protagonismo das populações originárias nos debates globais e argumenta pela necessidade de recusar o método hegemônico de ensinar antropologia. Por fim, sugerimos orientar os cursos introdutórios para a pluralidade de antropologias que compõem este campo de conhecimentos e suas condições de produção.

Palavras-chave: Teoria Antropológica; ensino de Antropologia; conhecimento; democratização da educação; renascimento indígena.

\section{LEARNING AND TEACHING ANTHROPOLOGIES}

\begin{abstract}
Based on two ethnographic cases about the authors own academic experiences, this paper aims to debate the importance of alternative Anthropological learning and teaching strategies in order to achieve the full reflexive potential of the discipline. In dialogue with scholars who critically reflect about Anthropology's colonial roots, we argue that the method of teaching Anthropology anchored on the duality between the Us and Them tends to produce anthropologists who identifies with the Us in this duality, a politically dangerous practice. The backgrounds of our analysis are the Brazilian democratization of universities and the phenomena of "Indigenous Renaissance", which stresses Original Populations centrality as actors in global debates. Finally, we contend that we need to reject such hegemonic method of teaching anthropology and invite teachers to orient undergraduate programs towards the plurality of anthropologies that composes this field, and its conditions of production.
\end{abstract}

Keywords: Anthropological Theory; Anthropology Teaching; knowledge; democratization of universities; indigenous renaissance.

RECEBIDO: $29 / 04 / 2020$

APROVADO: $20 / 01 / 2021$ 